Supplement of Hydrol. Earth Syst. Sci., 24, 4625-4639, 2020

https://doi.org/10.5194/hess-24-4625-2020-supplement

(c) Author(s) 2020. This work is distributed under

the Creative Commons Attribution 4.0 License.

(c) (1)

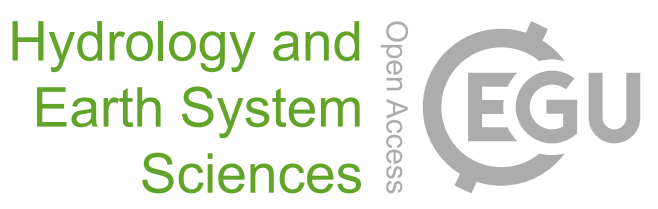

Supplement of

\title{
Global distribution of hydrologic controls on forest growth
}

\section{Caspar T. J. Roebroek et al.}

Correspondence to: Adriaan J. Teuling (ryan.teuling@wur.nl) and Caspar T. J. Roebroek (caspar.roebroek@env.ethz.ch)

The copyright of individual parts of the supplement might differ from the CC BY 4.0 License. 


\section{Supplement}

\section{Text S1: Confidence boundaries of correlation values}

To calculate the significance of correlation values, several statistical tools are available, as described in Rahman and Zhang (2016). In this study we use an adapted form of the t-test approach, because of it's computational efficiency: the confidence boundaries only depend on the number of samples. Therefore, these boundaries can be determined prior to the calculation of

5 the correlations. This approach, however, needs to be adapted slightly as the samples within each window are not independent. To do that, we introduce a $d f_{\text {offset }}$ parameter in the calculation of the degrees of freedom (see main text). This parameter is determined by comparing this methodology to two other ways of calculating confidence boundaries for correlation values: a permutation test and bootstrapping. The permutation test shuffles the data randomly and recalculates the correlation. By repeating this a thousand times a normal distribution (around zero) can be constructed. Everything above two standard deviations is considered statistically significant. For the bootstrapping the data is sampled with replacement, while keeping the connection between the data points. In doing so another normal distribution is created (centered around the true correlation value). Again we take two standard deviations as the threshold for significance. Both methods are applied to all the windows without missing data, and thus containing 225 data points. The thresholds for both methods are calculated as the median of the significance threshold for each window, to minimise the number of both false positives and false negatives. The final threshold value, used in this study is set to the average of these values. This approach is used for both the correlation between WTD and fAPAR, and between P/PET and fAPAR. The obtained threshold values are correlation values, which are converted to $d f_{\text {of } f s e t}$ by matching them to the critical correlation values with the t-test for different number of samples. The final distributions of the permutation test and bootstrapping, as well as the final chosen thresholds are depicted in Figure S7. To test the accuracy of this approach, the classification as described in the main text is done for South America (while not overlapping the moving window, to reduce computational burden), using all three methods. The overlap between the adapted t-test approach and the permutation test is 92 percent, and between the t-test and bootstrapping 95 percent (see Figure S8). This high degree of overlap convinced us of the independence of the main conclusions of the chosen metric. 


\section{Text S2: Landscape classification}

The landscape classes used in the study are based on the water table depth data of Fan et al. (2017). On this datasets two filters were applied; a mean $(\mu)$ and a standard deviation $(\sigma)$ kernel with a window size of 5 grid cells. These two maps were combined with the decision tree as shown in Figure S10. Wetlands (and open water) are classified according to the threshold chosen by Fan et al. (2013). The other classes are separated based on the local standard deviation with the following rational. (1) Water table depth mirrors altitude, especially in hilly and mountainous areas. (2) The standard deviation is a measure of the slope of the terrain. (3) Even in the Himalayas, every window of 5 by 5 grid cells contains a cell with surface water; with the rule that the maximum range should be 6 times the standard deviation, the highest class (High mountainous) should cover both surface water and a mountain of at least a 900 meters high. It is a relatively rough classification but it is visually acceptable when compared to global maps of wetlands and digital elevation models (two country scale visual validation examples are included in Figure S11 and S12). Changing the thresholds in the decision tree did not substantially change the main conclusions of the paper. The final map with landscape classes is shown in Figure S13. 


\section{References}

Beck, H., Zimmermann, N., McVicar, T. R., Vergopolan, N., Berg, A., and Wood, E. F.: Present and future Köppen-Geiger climate classification maps at 1-km resolution, Scientific Data, 5, 1-12, https://doi.org/10.1038/sdata.2018.214, http://dx.doi.org/10.1038/sdata.2018.214, 2018.

40 Fan, Y., Li, H., and Miguez-Macho, G.: Global Patterns of Groundwater Table Depth, Science, 339, 940-943, https://doi.org/10.1126/science.1229881, http://www.sciencemag.org/cgi/doi/10.1126/science.1229881, 2013.

Fan, Y., Miguez-Macho, G., Jobbágy, E. G., Jackson, R. B., and Otero-Casal, C.: Hydrologic regulation of plant rooting depth, Proceedings of the National Academy of Sciences, 114, 10572 -10 577, https://doi.org/10.1073/pnas.1712381114, https://www.pnas.org/content/114/ 40/10572, 2017.

45 Fick, S. E. and Hijmans, R. J.: WorldClim 2: new 1-km spatial resolution climate surfaces for global land areas, International Journal of Climatology, 37, 4302-4315, https://doi.org/10.1002/joc.5086, http://doi.wiley.com/10.1002/joc.5086, 2017.

Hartemink, A. E. and Sonneveld, M. P.: Soil maps of The Netherlands, Geoderma, 204-205, 1-9, https://doi.org/10.1016/j.geoderma.2013.03.022, 2013.

Myneni, R., Knyazikhin, Y., and Park, T.: MCD15A3H MODIS/Terra+Aqua Leaf Area Index/FPAR 4-day L4 Global 500m SIN Grid V006 [Data set], https://doi.org/10.5067/MODIS/MCD15A2H.006, 2015.

Rahman, M. and Zhang, Q.: Comparison among pearson correlation coefficient tests, Far East Journal of Mathematical Sciences, 99, 237255, https://doi.org/10.17654/MS099020237, 2016.

Simard, M., Pinto, N., Fisher, J. B., and Baccini, A.: Mapping forest canopy height globally with spaceborne lidar, Journal of Geophysical Research, 116, 4021, https://doi.org/10.1029/2011JG001708, https://agupubs.onlinelibrary.wiley.com/doi/full/10.1029/2011JG001708, 2011.

Trabucco, A. and Zomer, R. J.: Global Aridity Index and Potential Evapotranspiration (ET0) Climate Database v2, CGIAR Consortium for Spatial Information (CGIAR-CSI), p. 10, https://doi.org/10.6084/m9.figshare.7504448.v3, https://figshare.com/articles/ Global\{_\}Aridity $\left\{_{-}\right\} \operatorname{Index}\left\{_{-}\right\}$and $\left\{_{-}\right\}$Potential $\left\{_{-}\right\}$Evapotranspiration $\left\{_{-}\right\} \operatorname{ET} 0\left\{_{-}\right\}$Climate $\left\{_{-}\right\}$Database $\left\{_{-}\right\} \mathrm{v} 2 / 7504448\{\%\} 0 \mathrm{Ahttps:}$ //ndownloader.figshare.com/files/13901336\{\%\}0Ahttps://ndownloader.figshare.com/files/13901324\{\%\}0Ahttps://ndownloader.figshare. com/file, 2018.

Van Overmeeren, R. A.: Radar facies of unconsolidated sediments in The Netherlands: A radar stratigraphy interpretation method for hydrogeology, Journal of Applied Geophysics, 40, 1-18, https://doi.org/10.1016/S0926-9851(97)00033-5, 1998.

Zomer, R. J., Trabucco, A., Bossio, D. A., and Verchot, L. V.: Climate change mitigation: A spatial analysis of global land suitability for clean development mechanism afforestation and reforestation, Agriculture, Ecosystems and Environment, 126, 67-80, https://doi.org/10.1016/j.agee.2008.01.014, www.elsevier.com/locate/agee, 2008. 


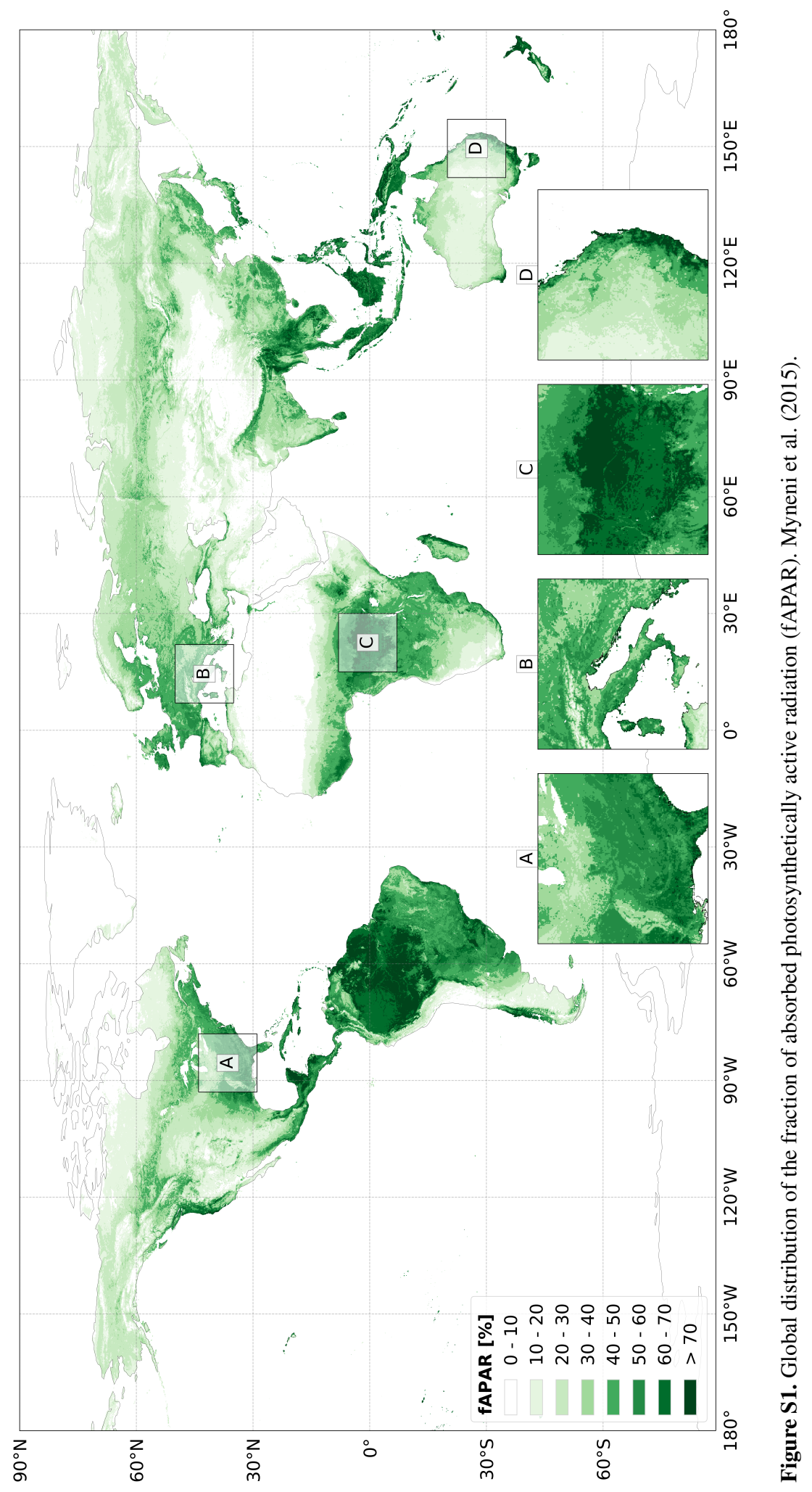




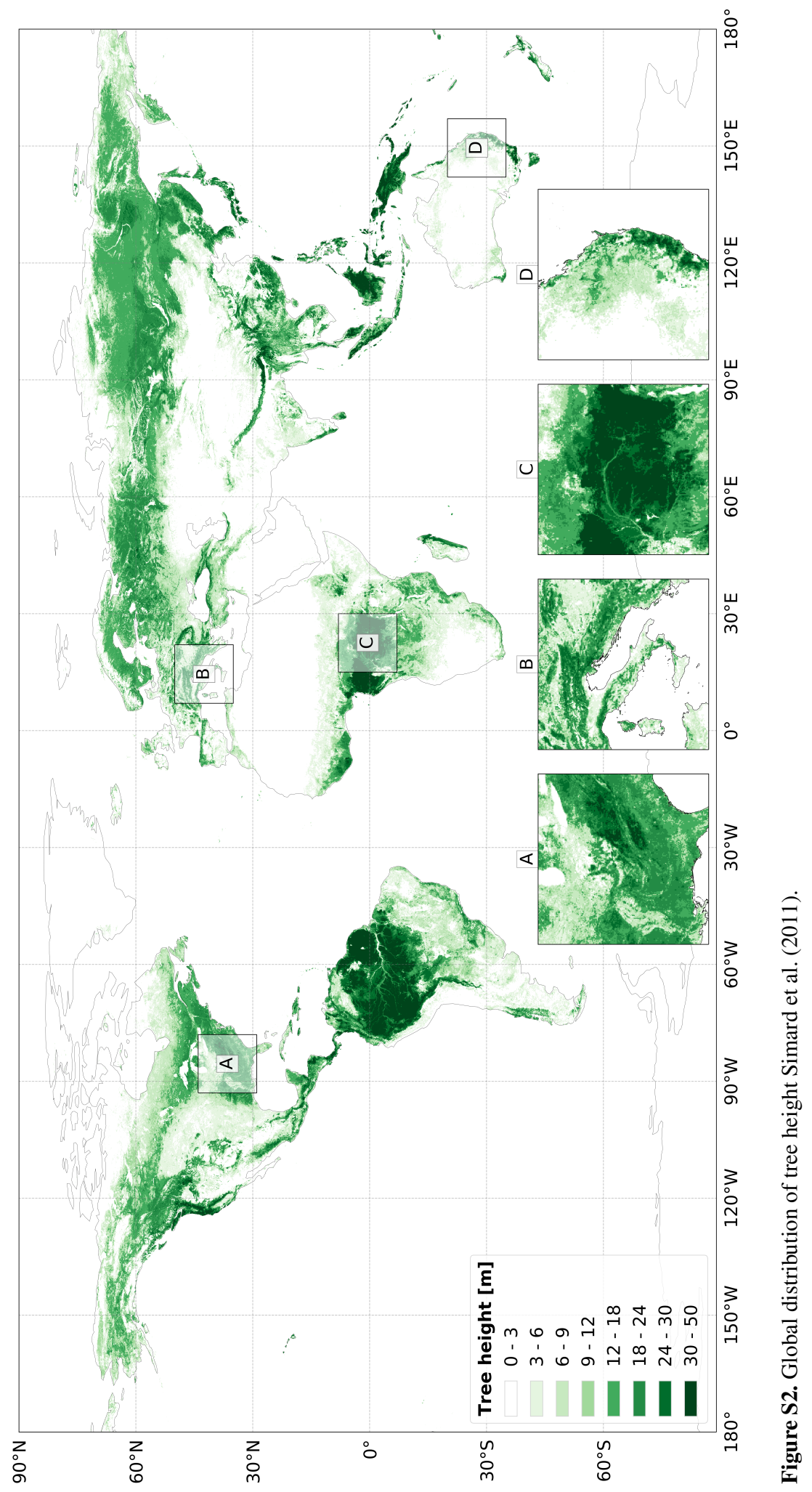




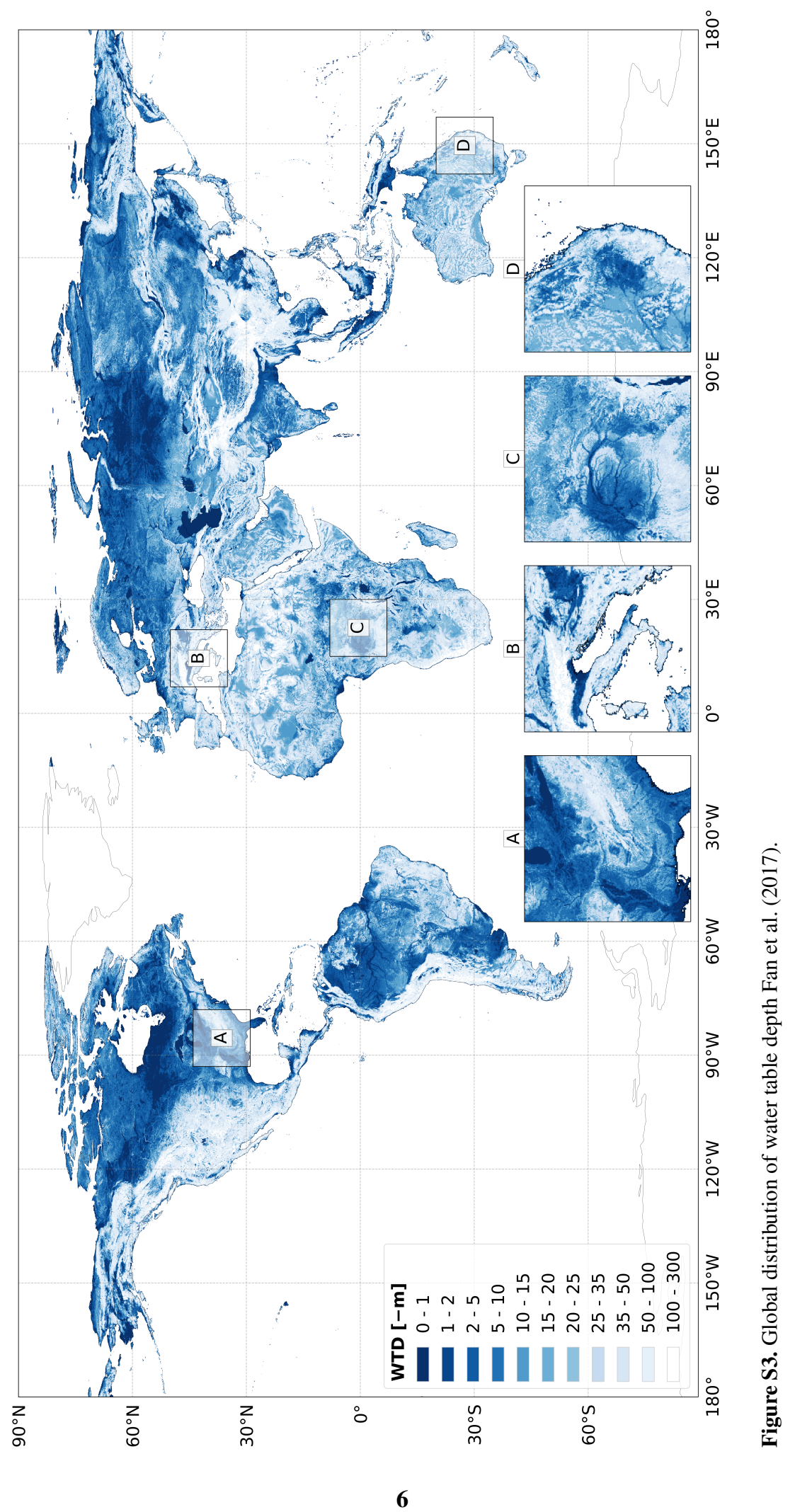









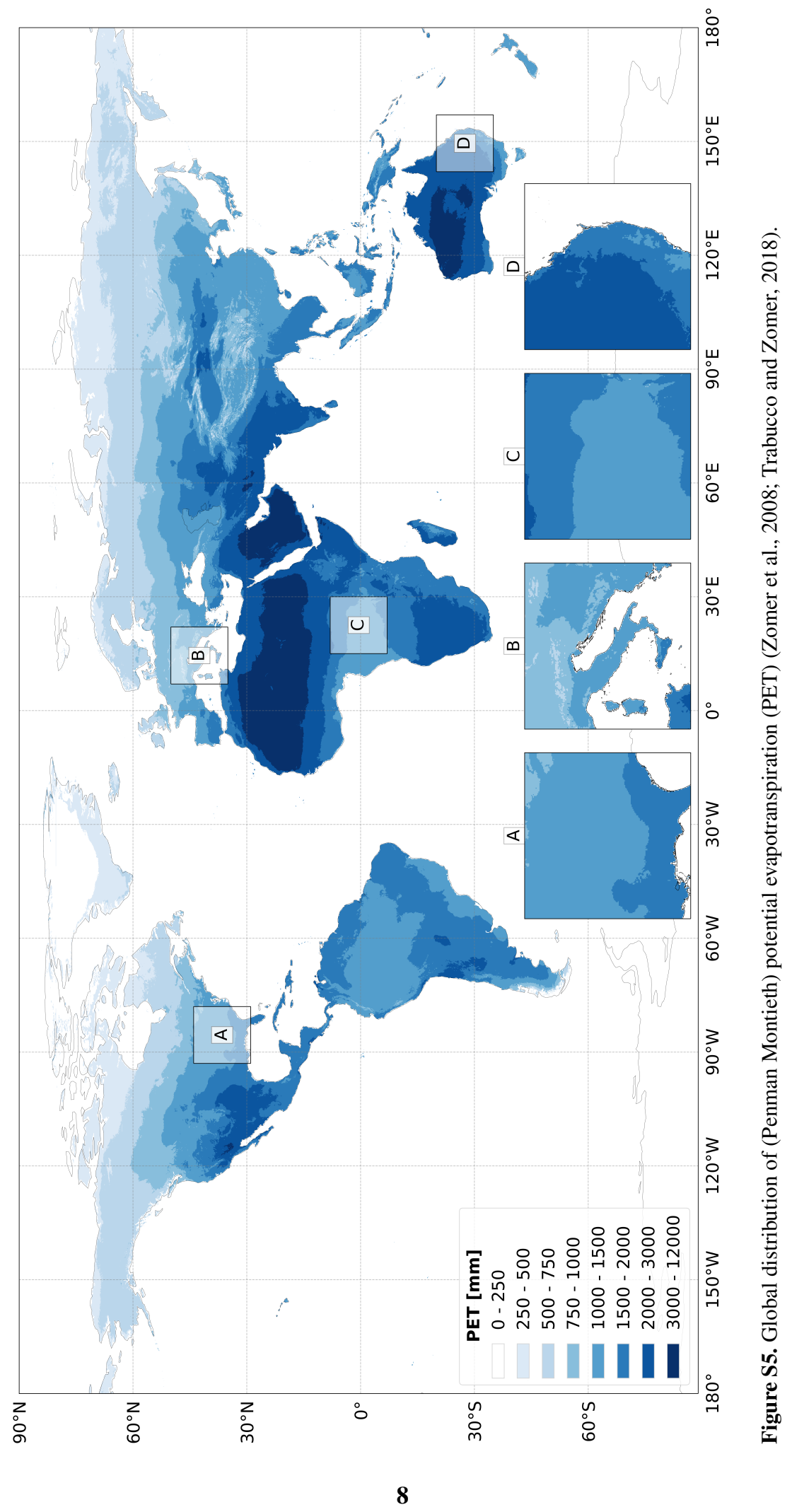




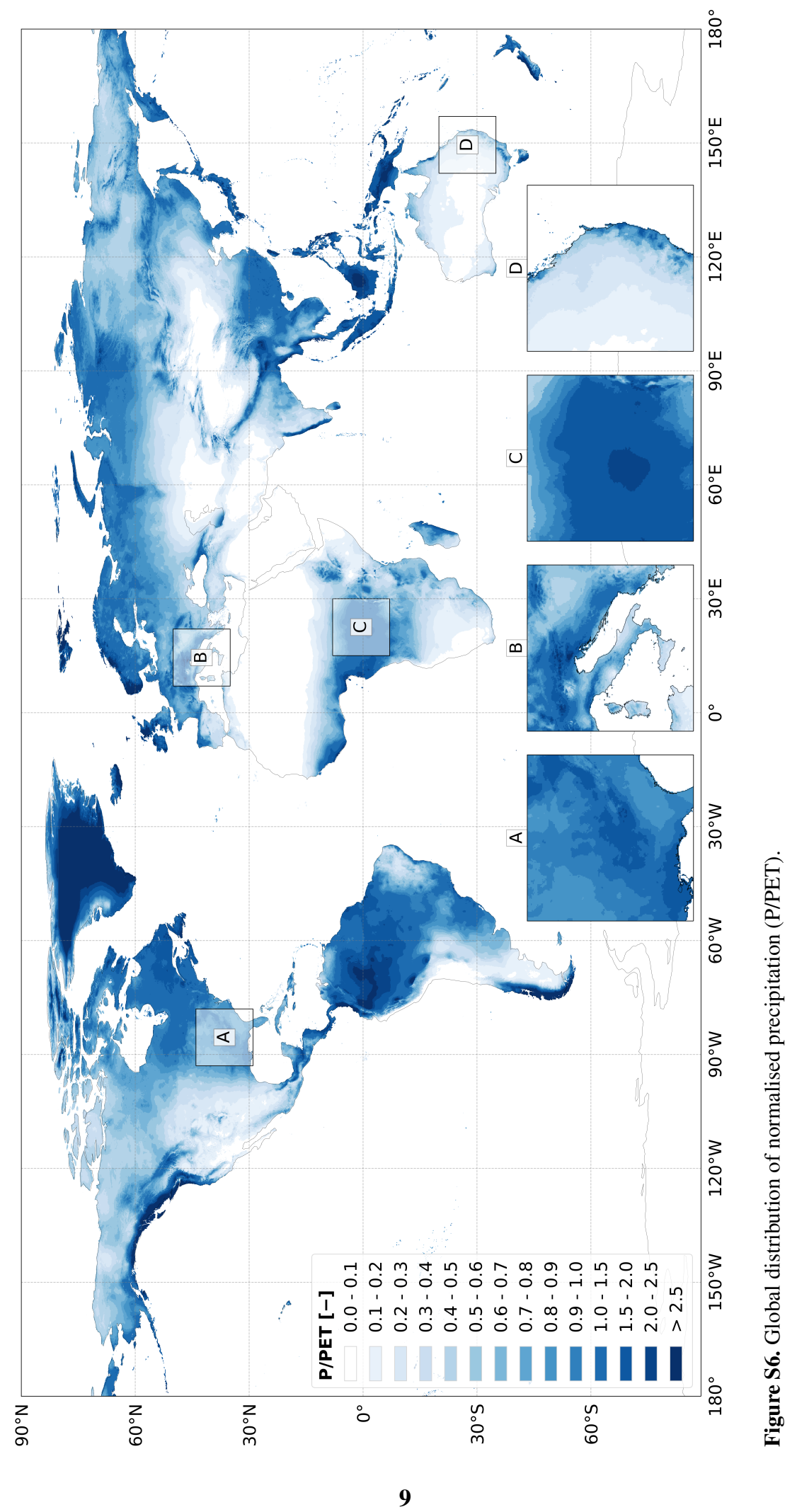



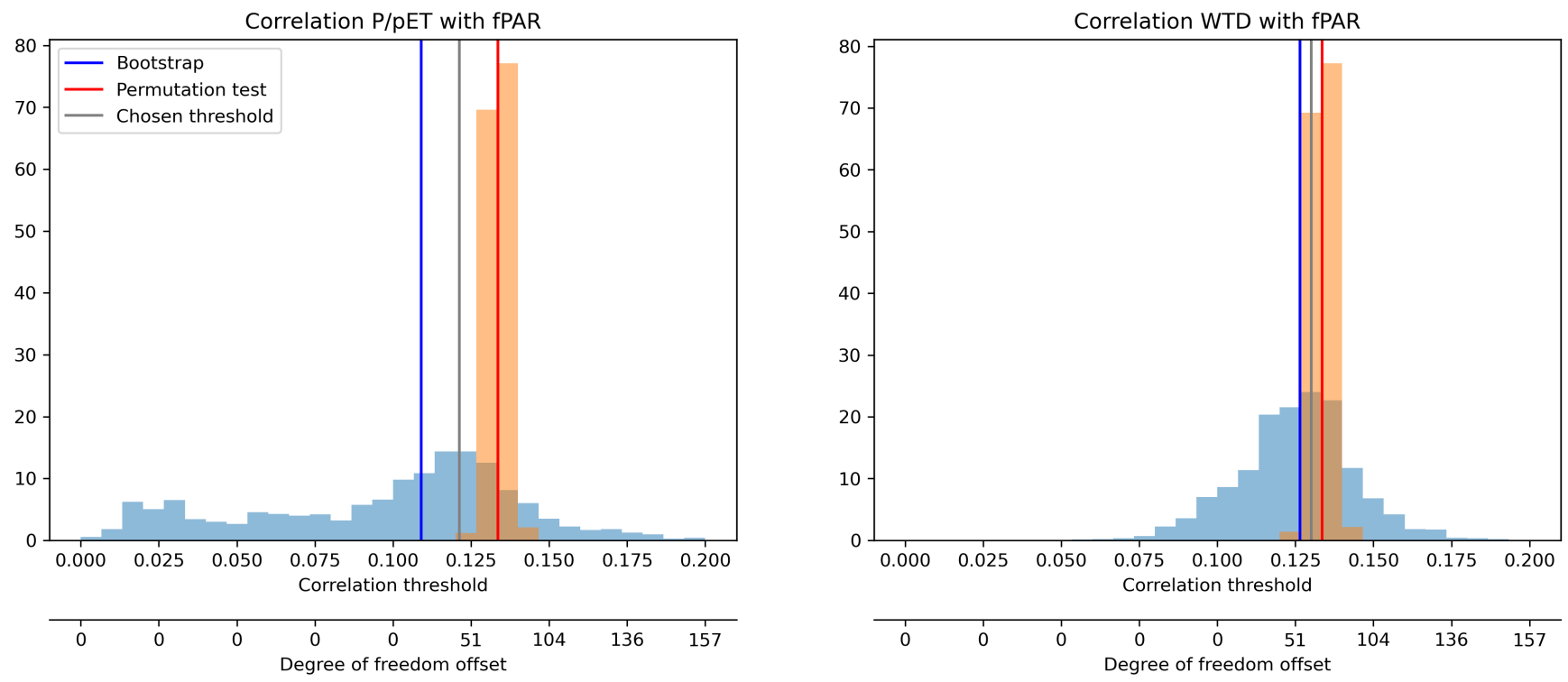

Figure S7. Significant correlation values for the correlation between WTD and fAPAR, and P/PET and fAPAR. The chosen threshold is the average of the median values, as obtain by performing a bootstrapping analysis and permutation test on all windows without missing data (225 data points). 

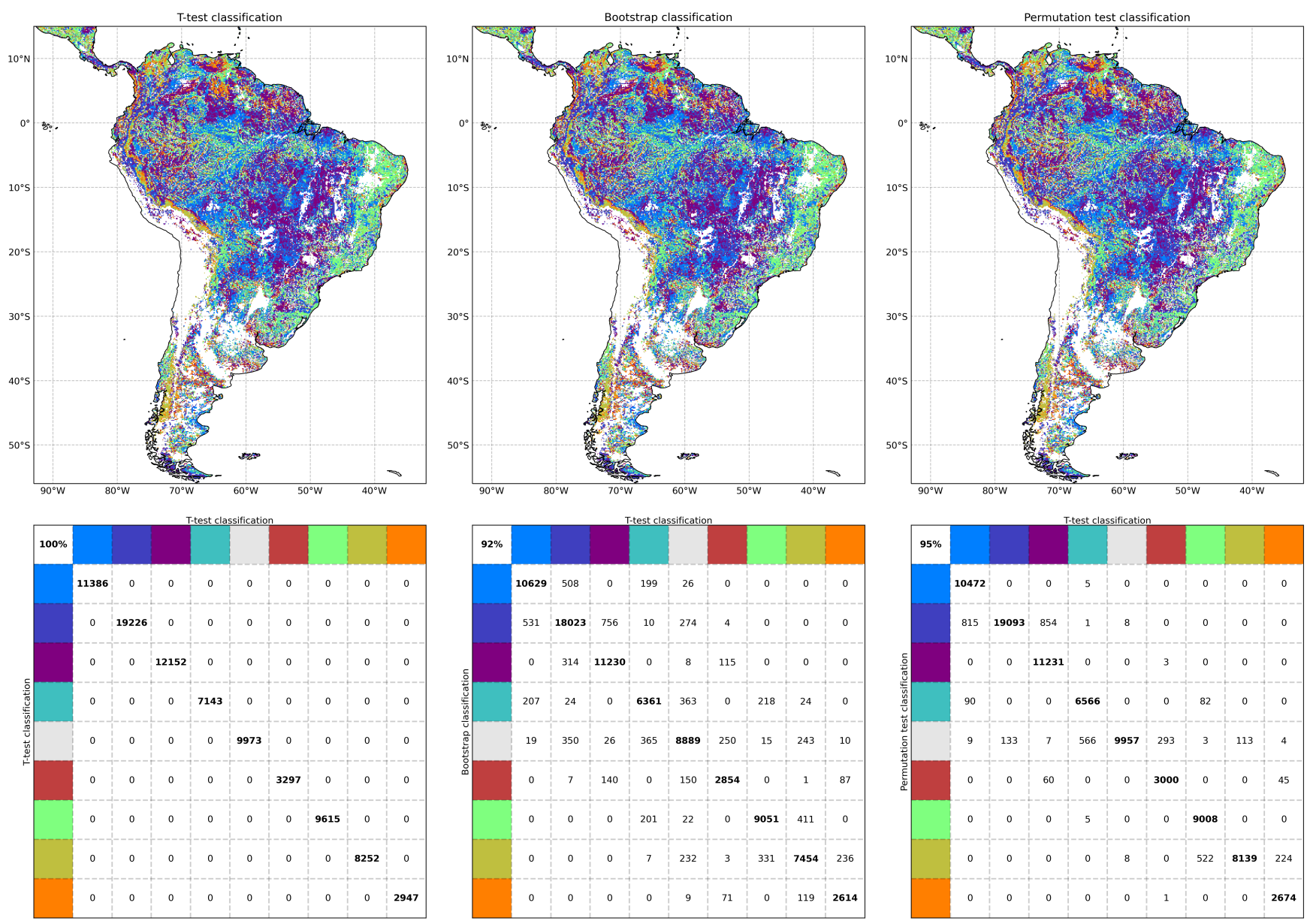

Figure S8. Classification of the correlation as described in the main text. The confusion matrices describe respectively a 92 and 95 percent overlap between the adapted t-test approach and bootstrapping / permutation test. 


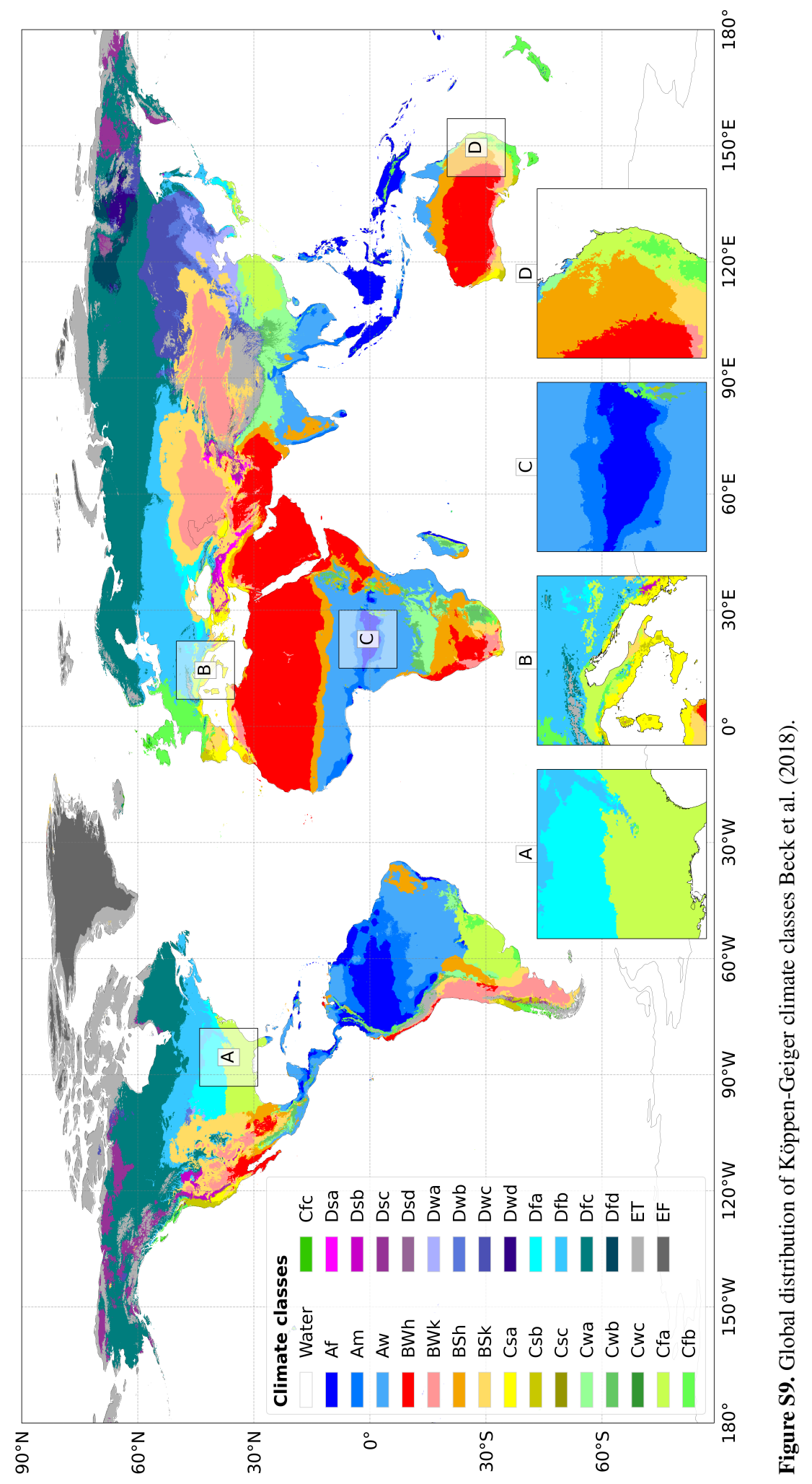






Figure S10. Decision tree used to create global landscape classes as depicted in Figure S13. The building blocks $\mu$ and $\sigma$ are two datasets created by applying a sliding windows on the dataset of water table depth depicted in Figure S3. $\mu$ corresponds with a mean kernel, $\sigma$ with a standard deviation kernel. 


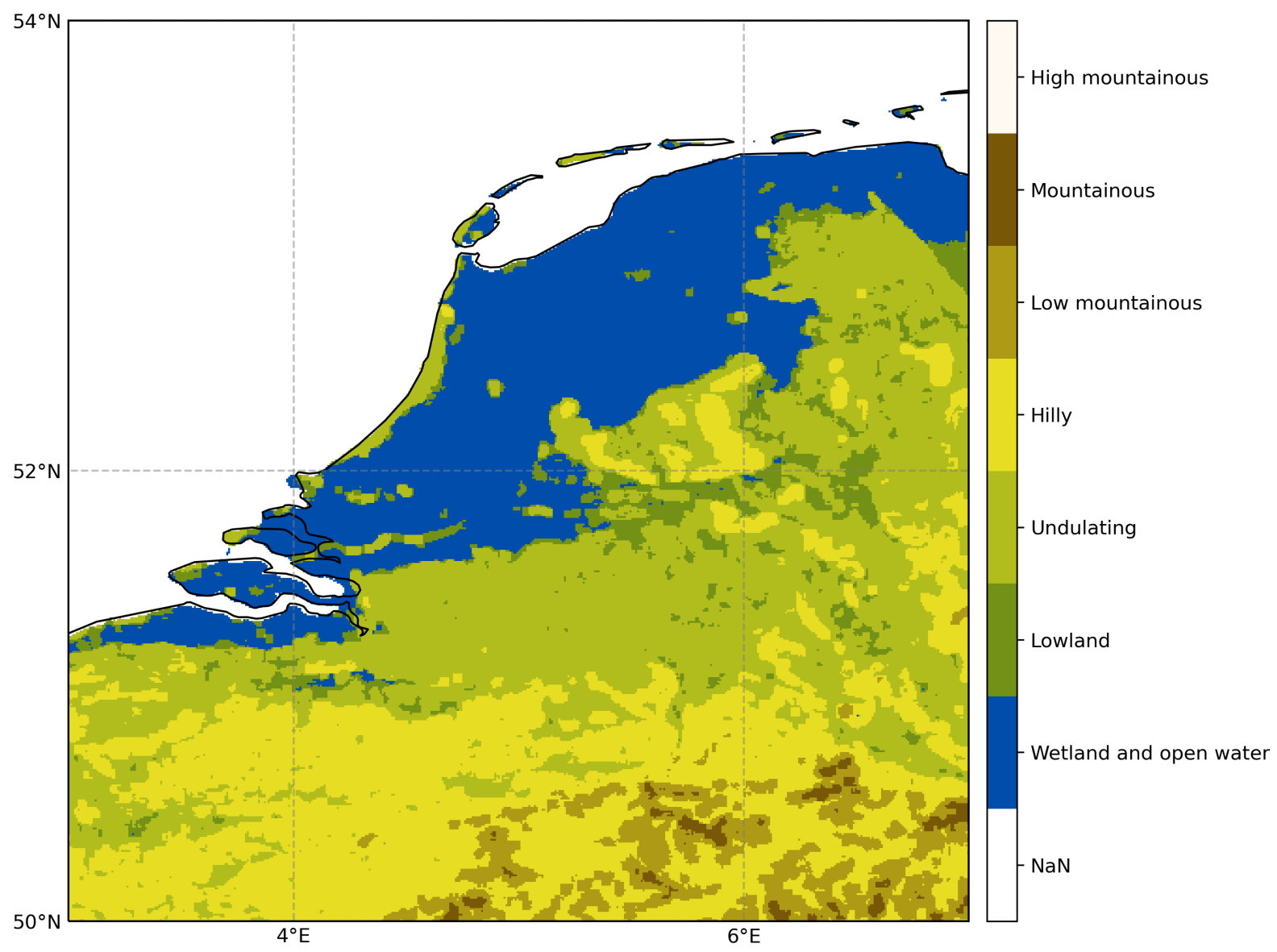

Figure S11. Landscape class validation example showing The Netherlands. The biggest landscape unit, the wetland and open water class, defines most of the west and north of the Netherlands, the areas with extensive lowland polders (Hartemink and Sonneveld, 2013). Smaller landscape units are visible as well; the coastal dunes in the west of the Netherlands and the individual push moraines in the Veluwe complex (central Netherlands) can be distinguished (for referhence see Van Overmeeren (1998)). Also, smaller units are visible such as the river levees of both the Meuse and Waal (the last part of the Rhine) 


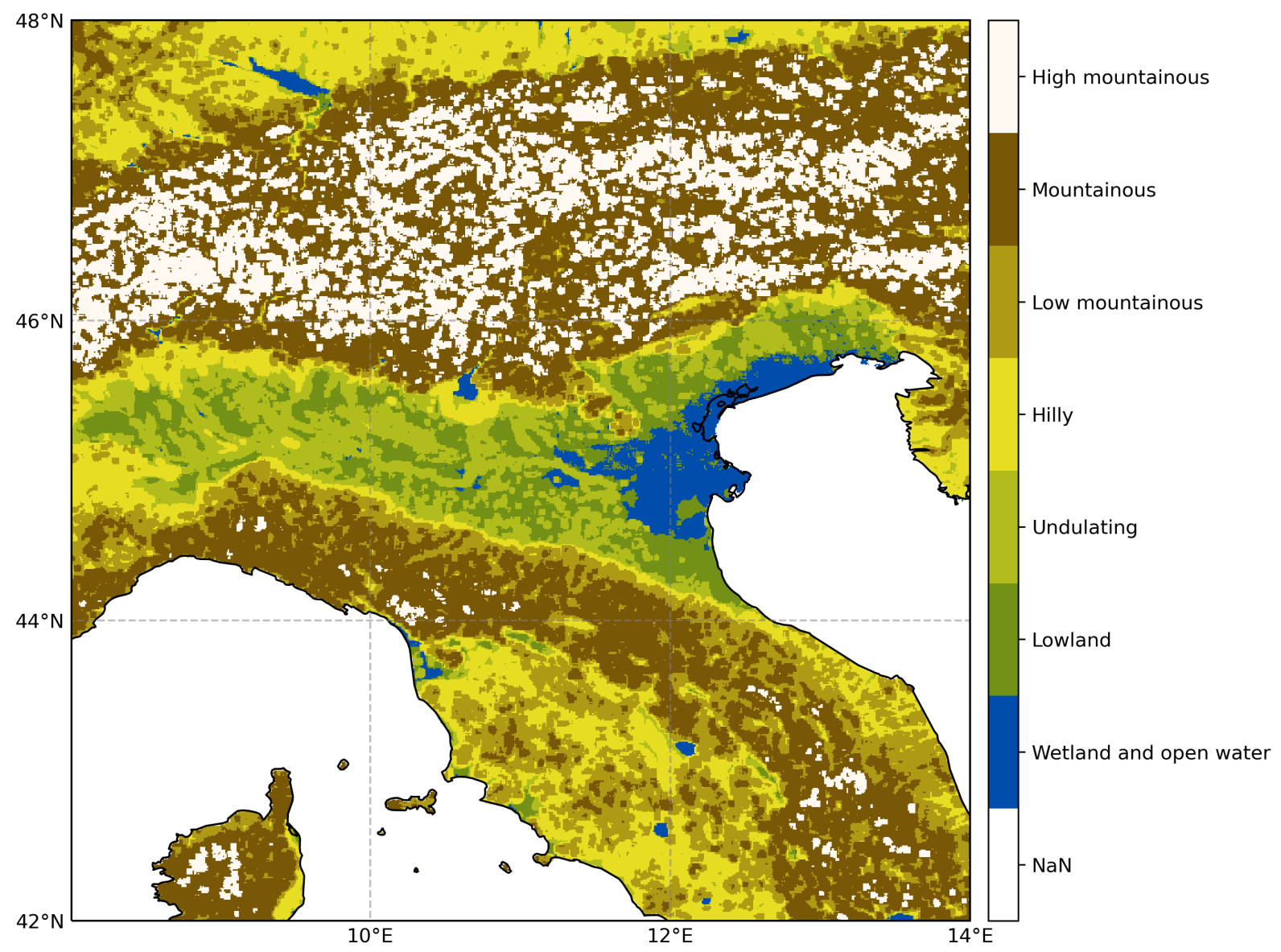

Figure S12. Landscape class validation example showing northern Italy. The Alps show up as the highest locations in this example, with some detail in this mountainous area. The Apennines appear as mountainous but clearly lower than the Alps. In between, the Po valley shows up as low lying area and the delta (close to Venice) shows up as wetland and open water. Smaller landscape units are picked up as well, e.g. Lago di Garda, one of the biggest lakes in this region, and the Euganean Hills (protrusions in the Po valley of volcanic origin). 


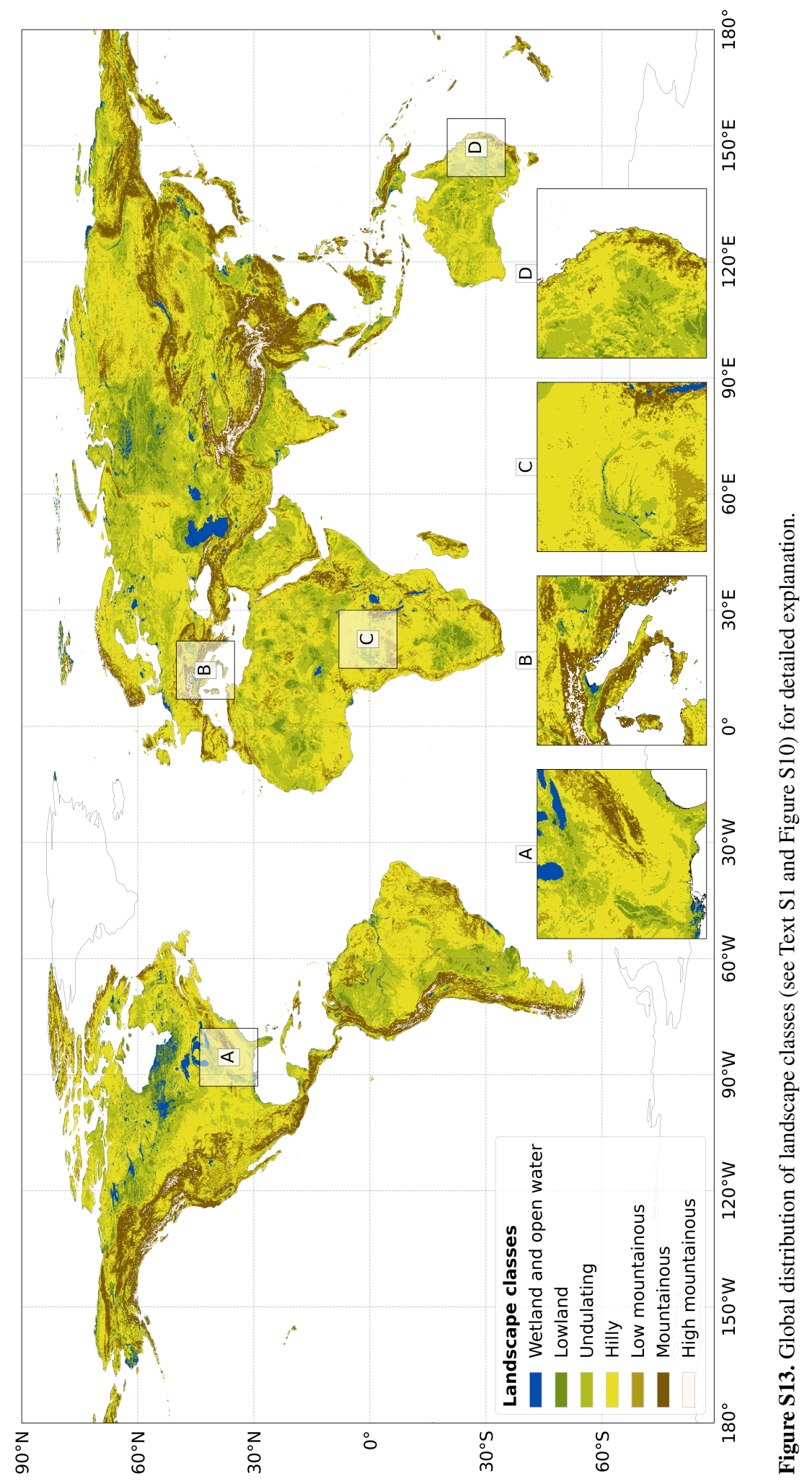




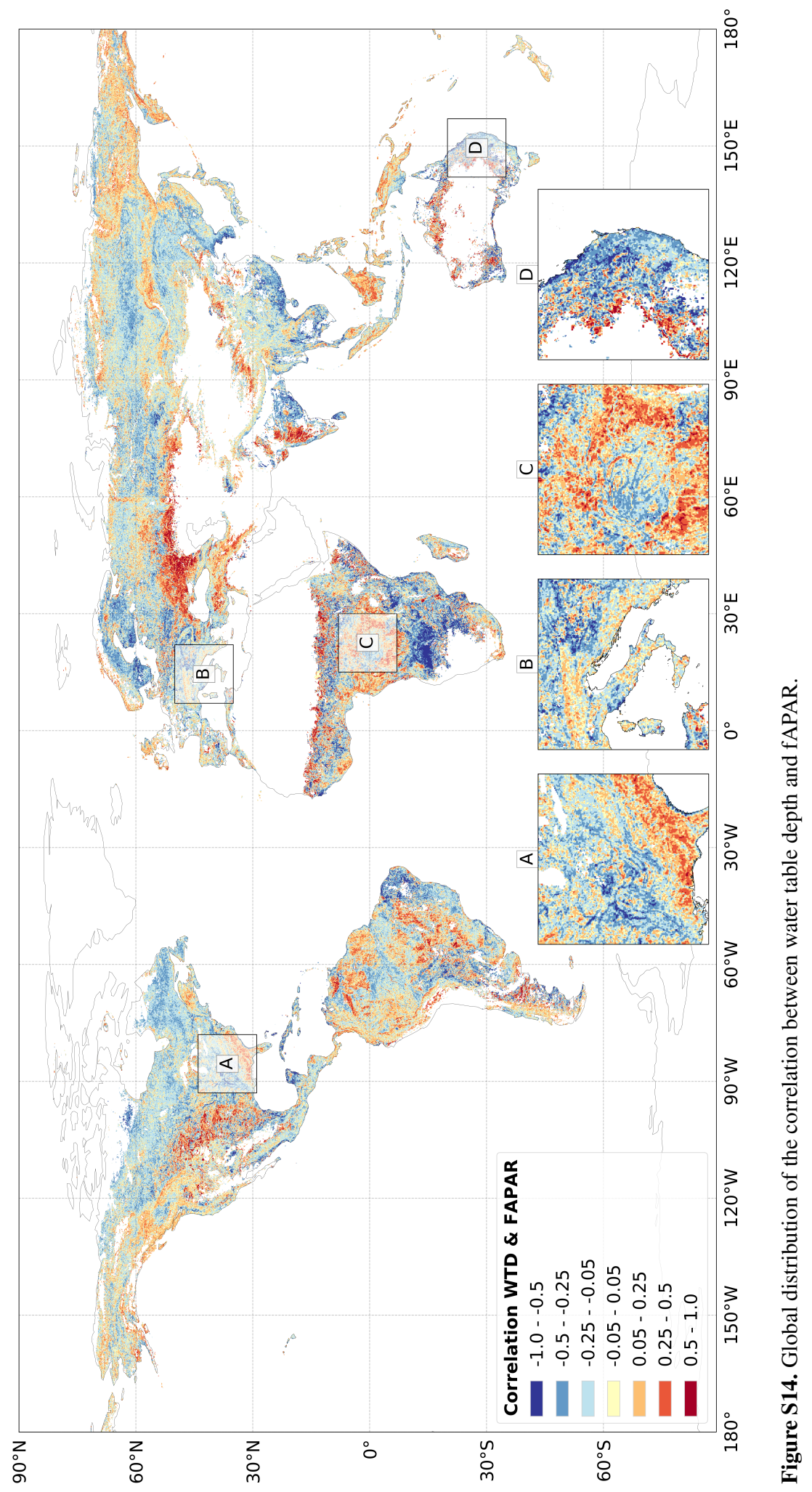




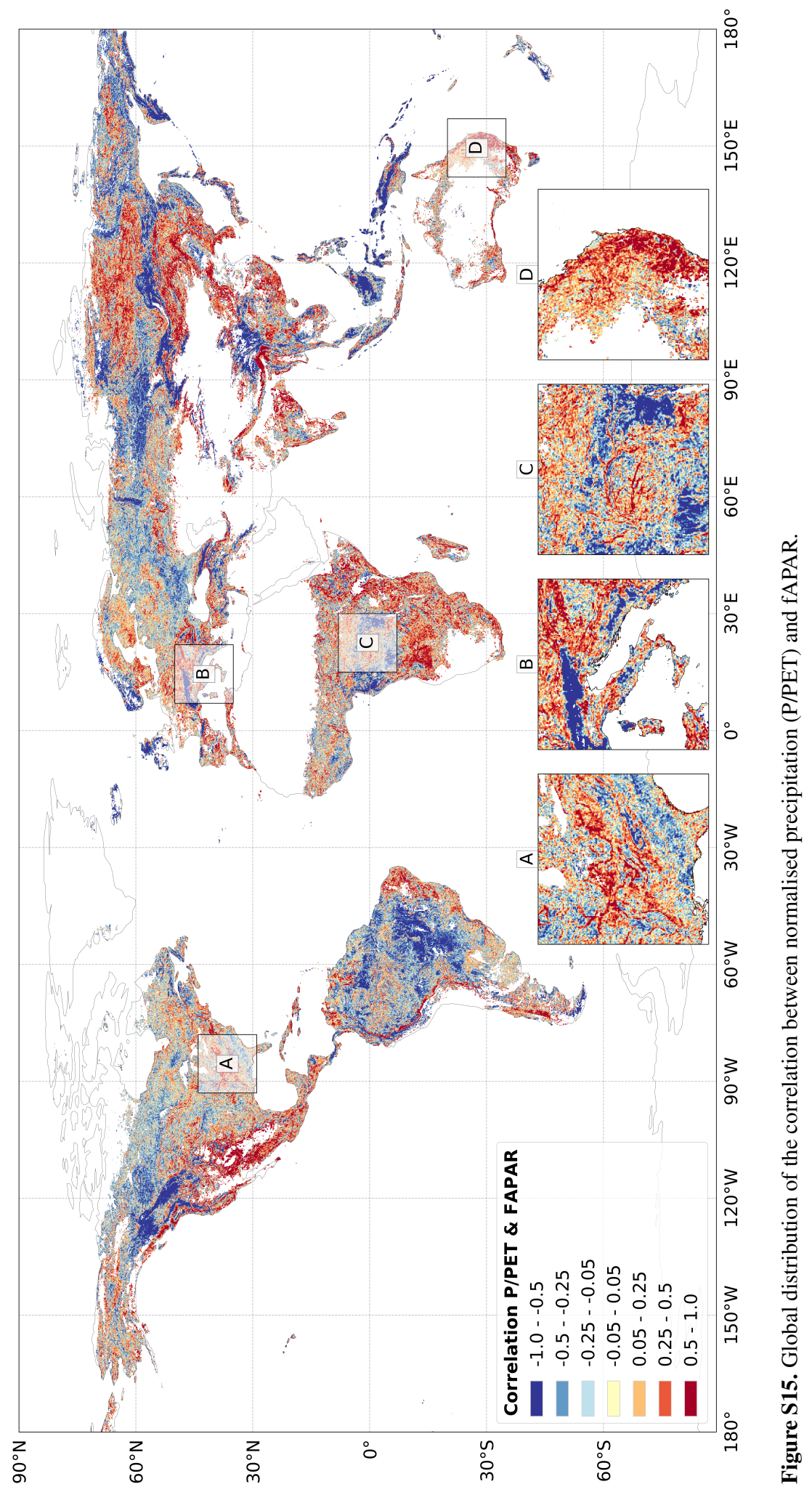




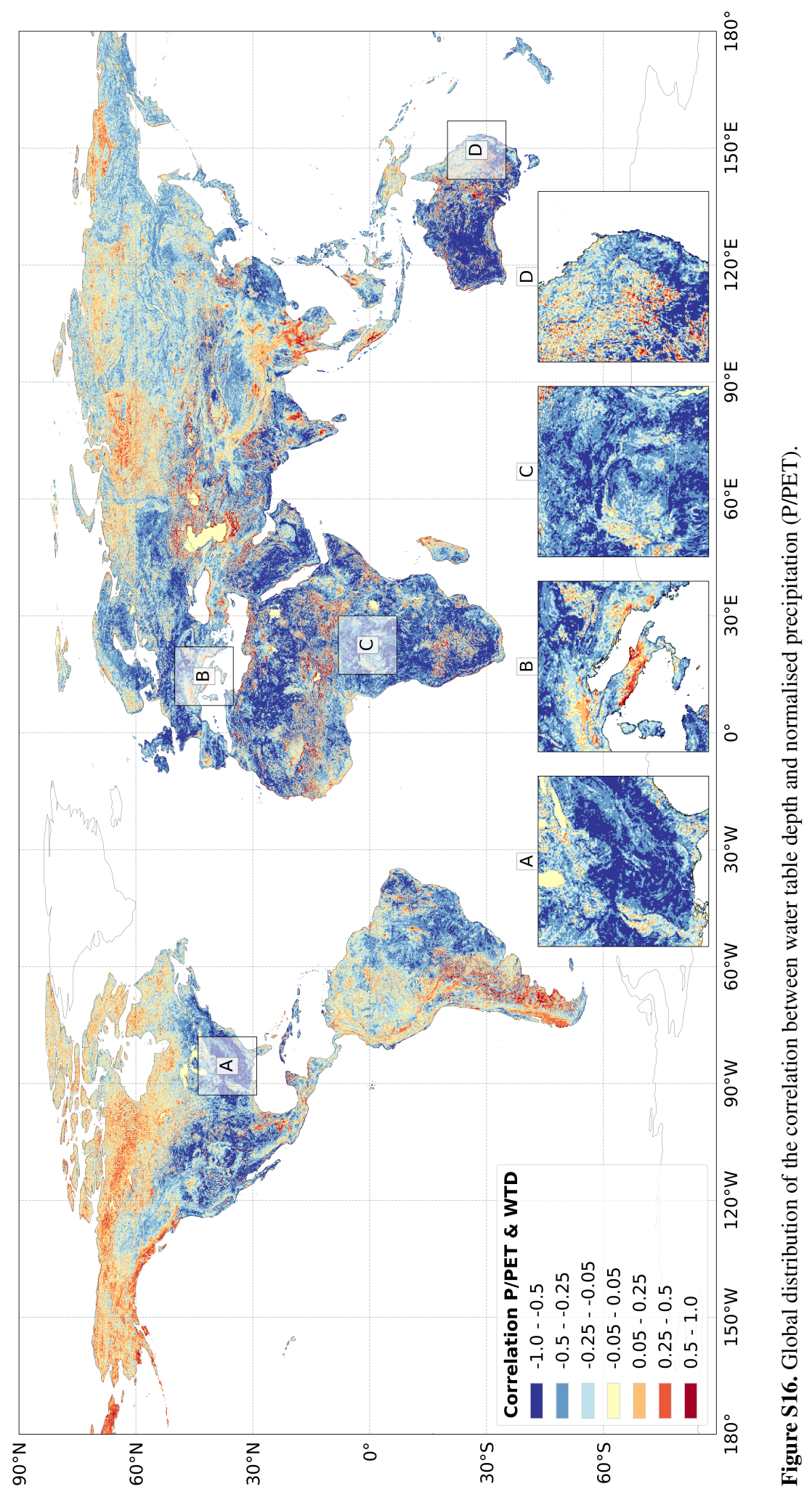








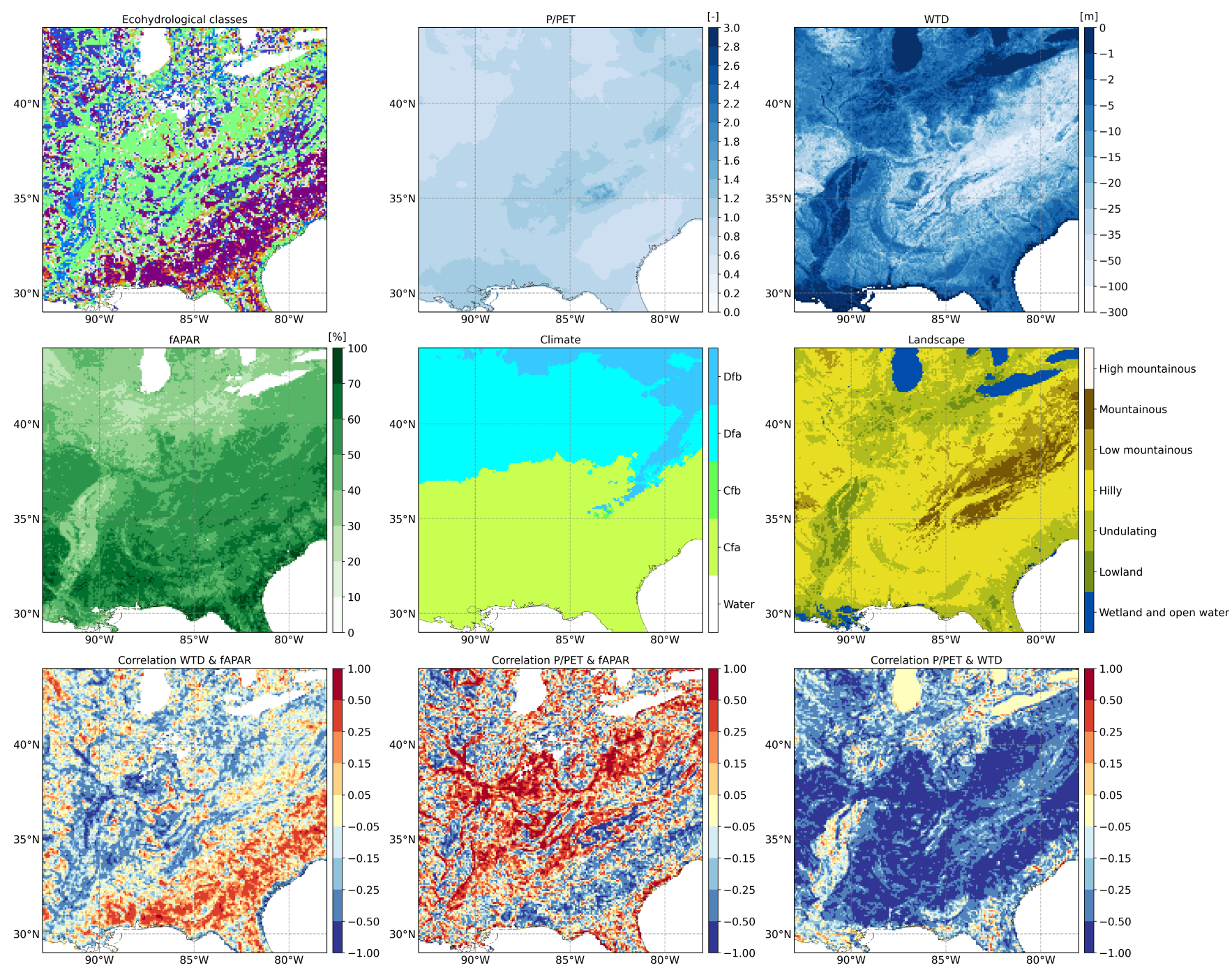

Figure S18. These maps depict the Mississippi river valley on the left and the southern part of the American East Coast on the right. For the interpretation of these figures see the main text. 

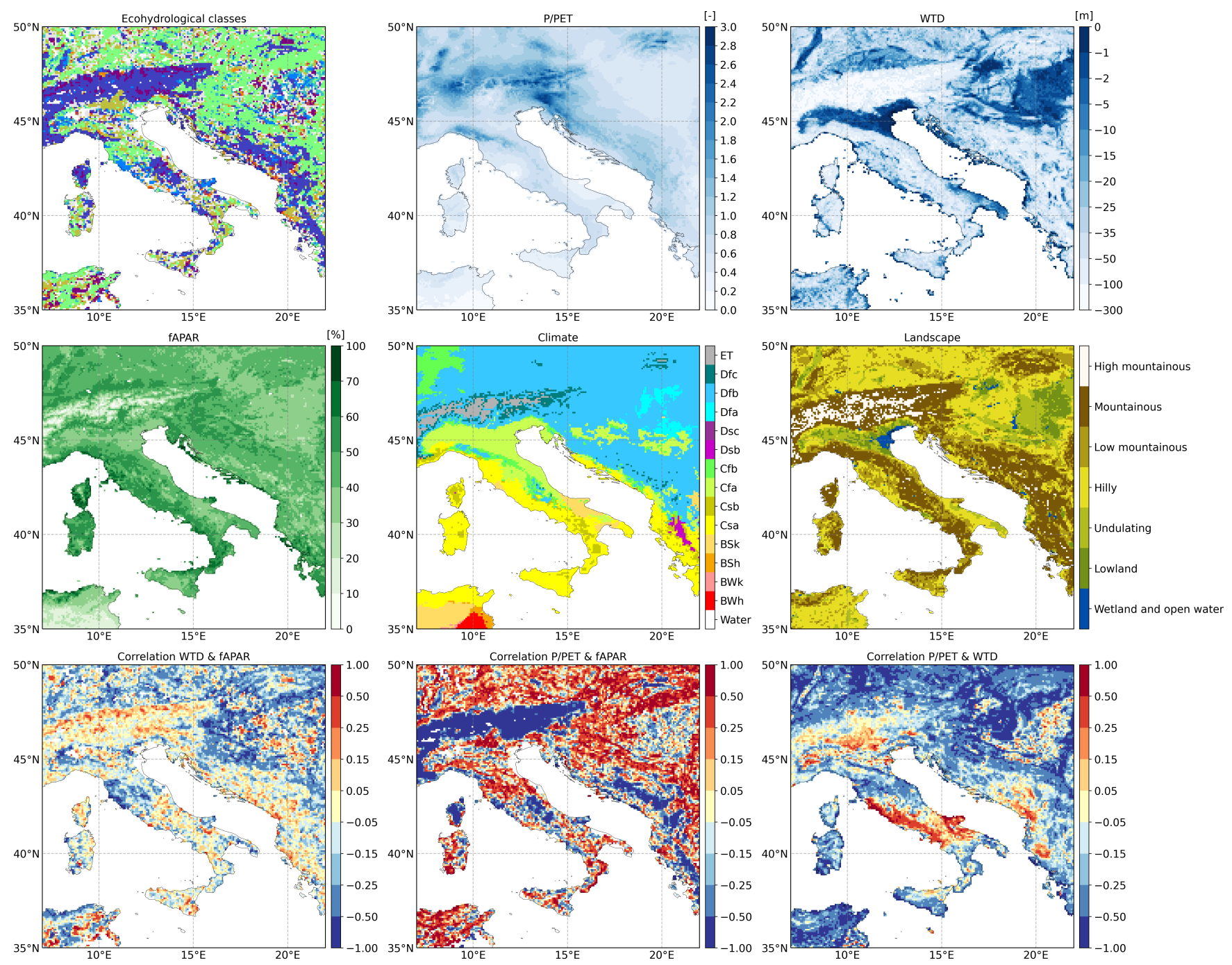

Figure S19. These maps depict South-Eastern Europe with the Alps. For the interpretation of these figures see the main text. 

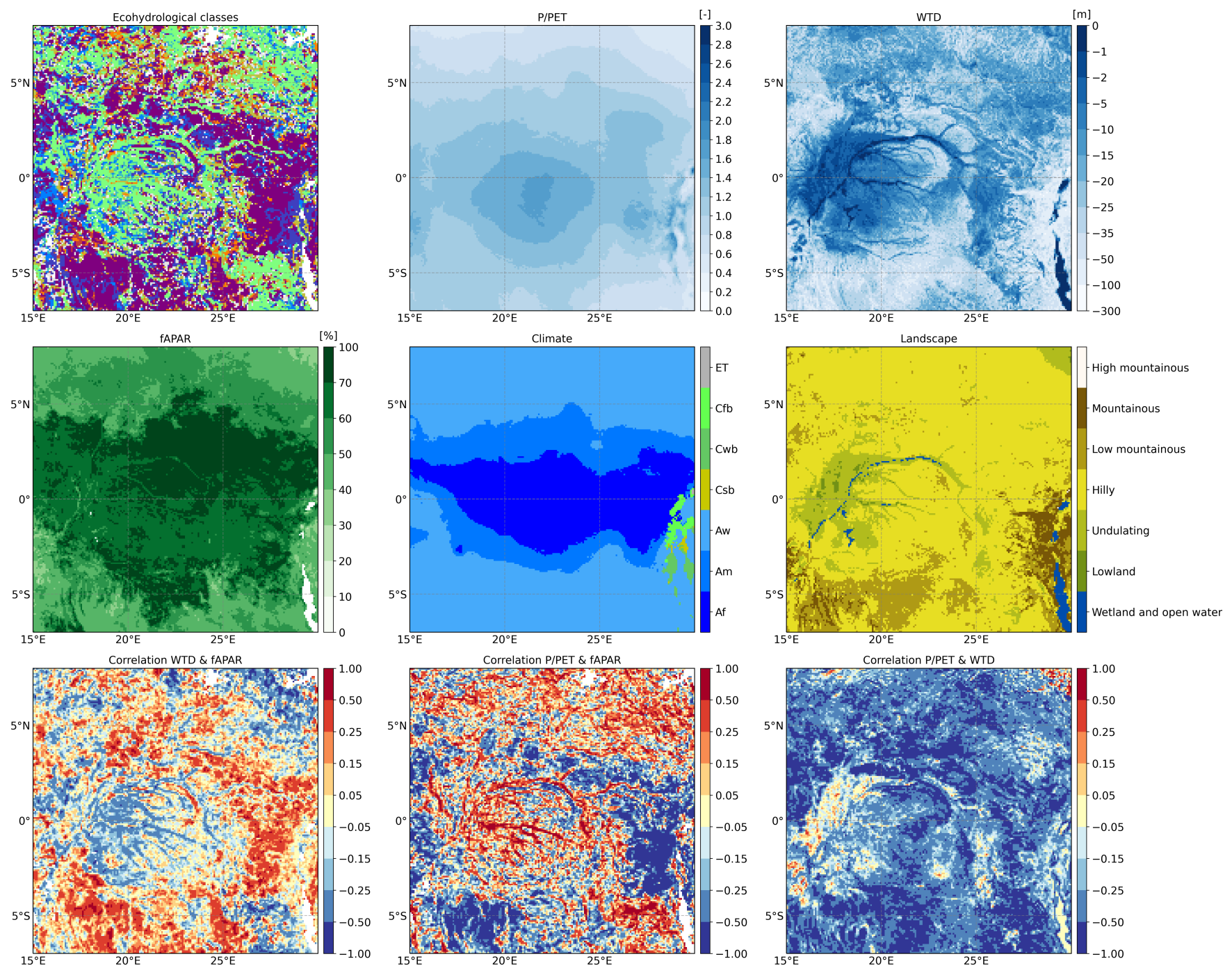

Figure S20. These maps depict the Congo river basin. For the interpretation of these figures see the main text. 

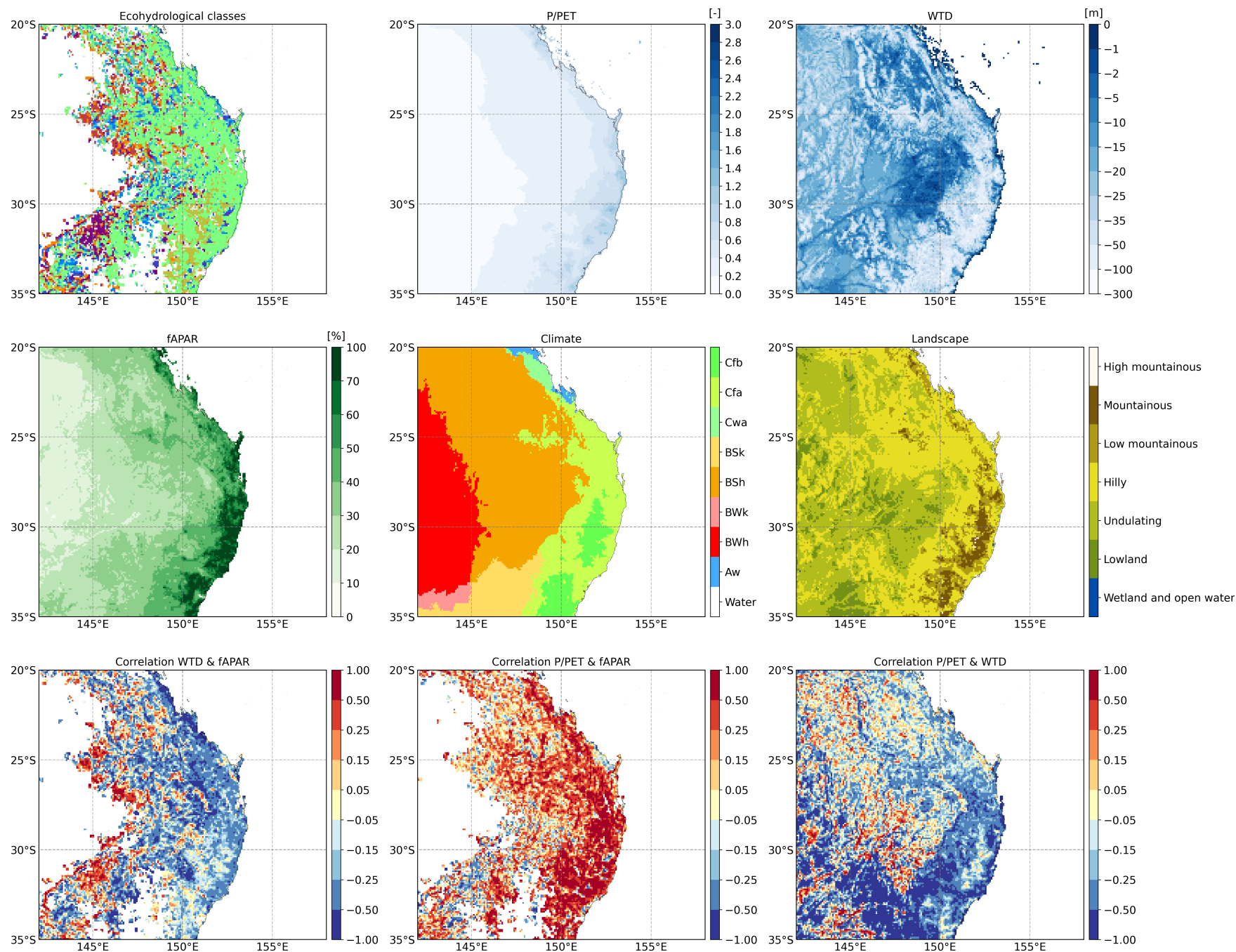

Figure S21. These maps depict Eastern Australia. For the interpretation of these figures see the main text. 

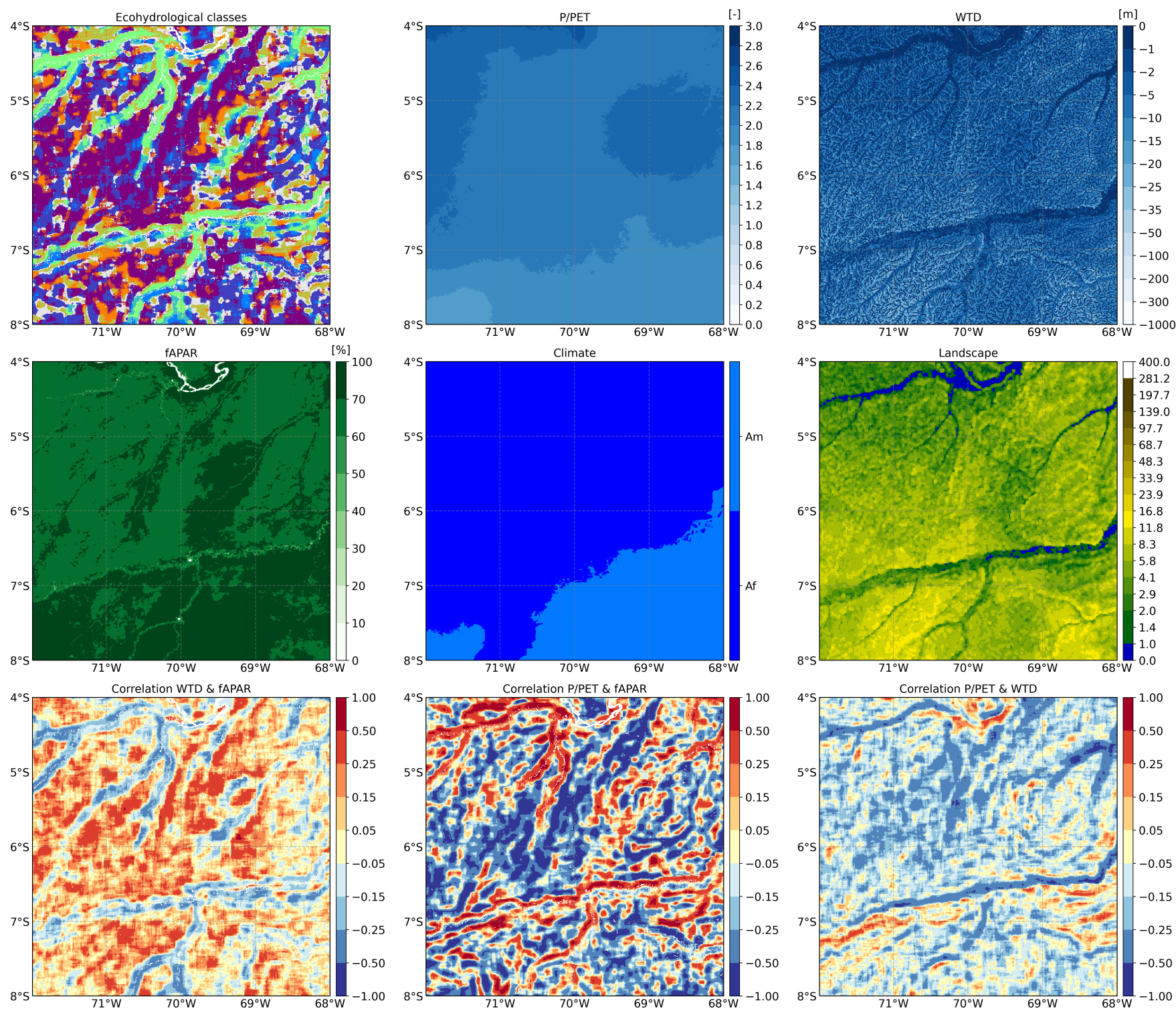

Figure S22. Subset of the data at their original resolution of 30 arc-seconds. The map depicts a part of the State of Amazonas in the west of Brazil. It displays a part of Figure 4 of the main paper of section 3.2, where the patterns displayed here are discussed. 

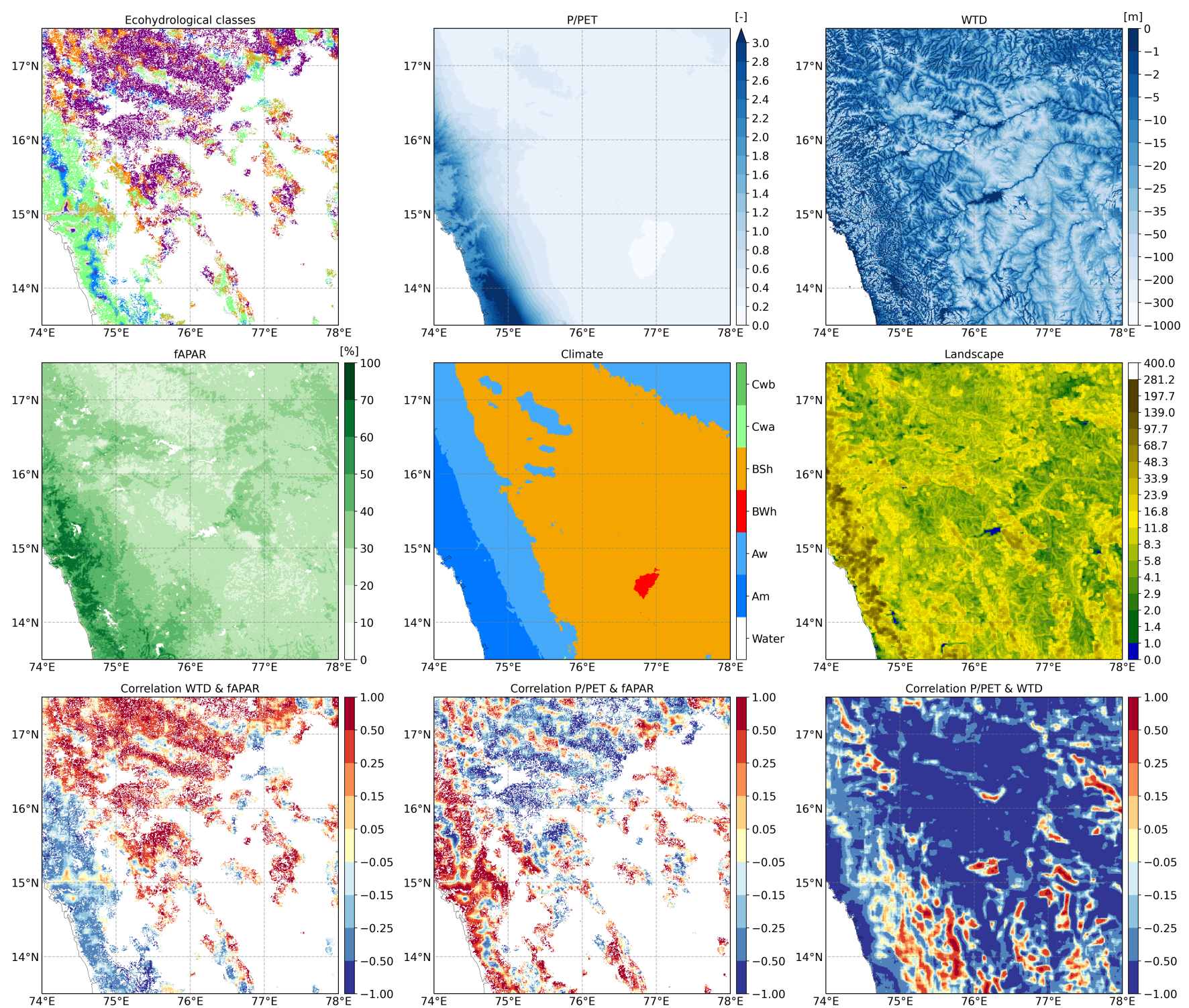

Figure S23. Subset of the data at their original resolution of 30 arc-seconds. The map depict a part of India, a subset of the maps displayed in Figure 5 of the main paper. In section 3.2 the patterns displayed here are discussed. 


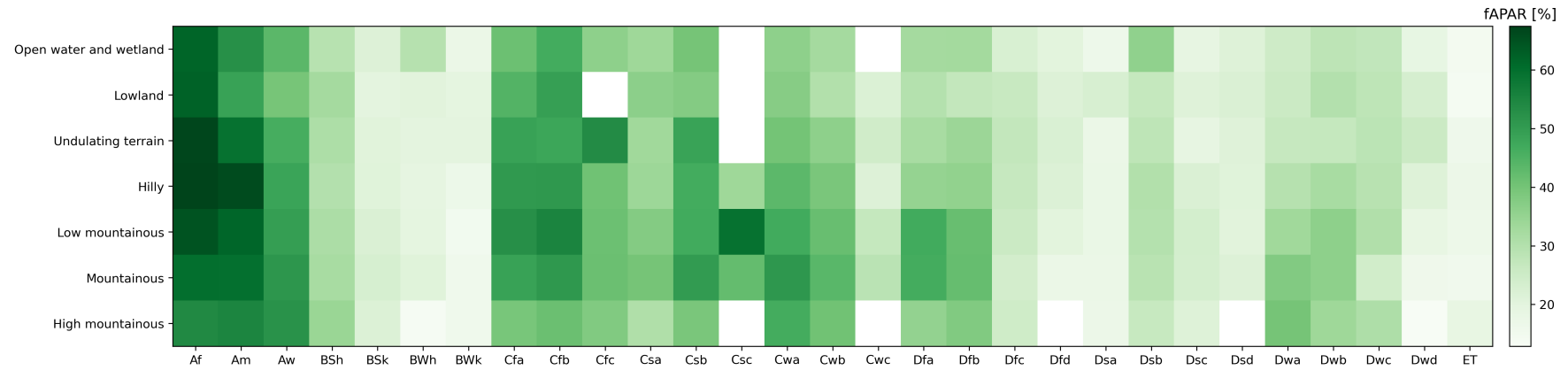

Figure S24. Mean fAPAR in different climate and landscape positions. White signifies that the combination of landscape and climate did not appear in the data.

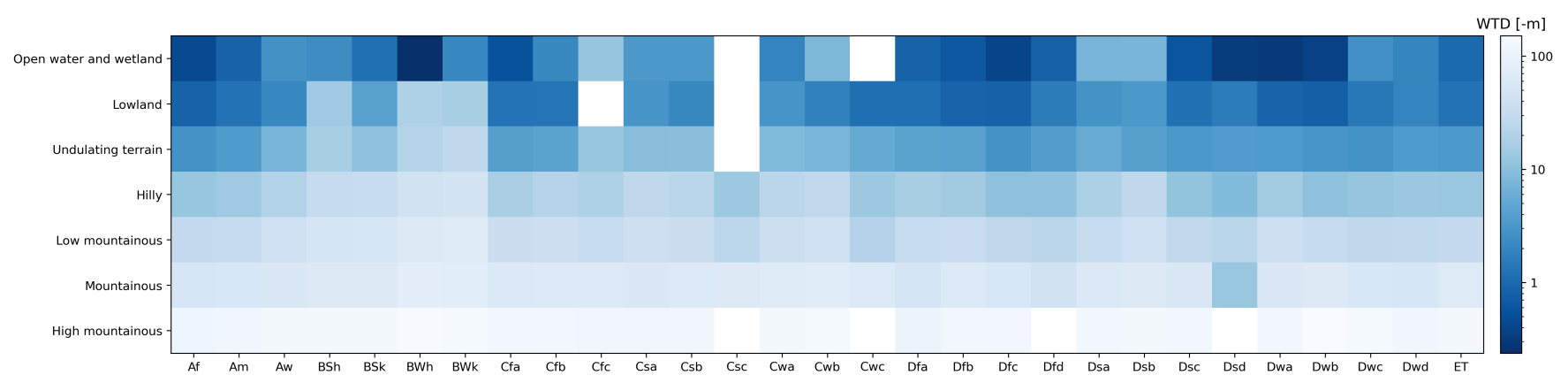

Figure S25. Mean WTD in different climate and landscape positions. White signifies that the combination of landscape and climate did not appear in the data.

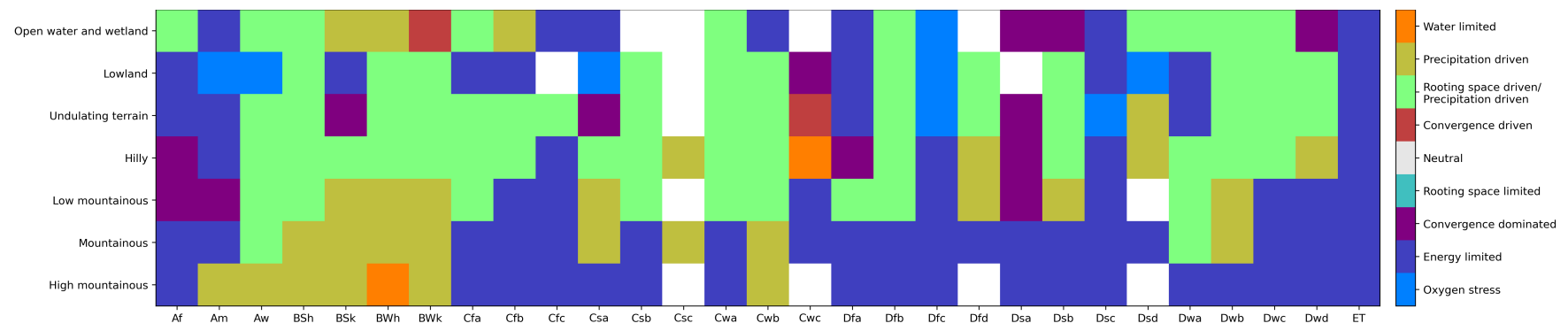

Figure S26. Prevalent class in different climate and landscape positions. For an explanation of the different classes see Figure 1 of the main text. White signifies that the combination of landscape and climate did not appear in the data or two classes are present in equal amounts. 

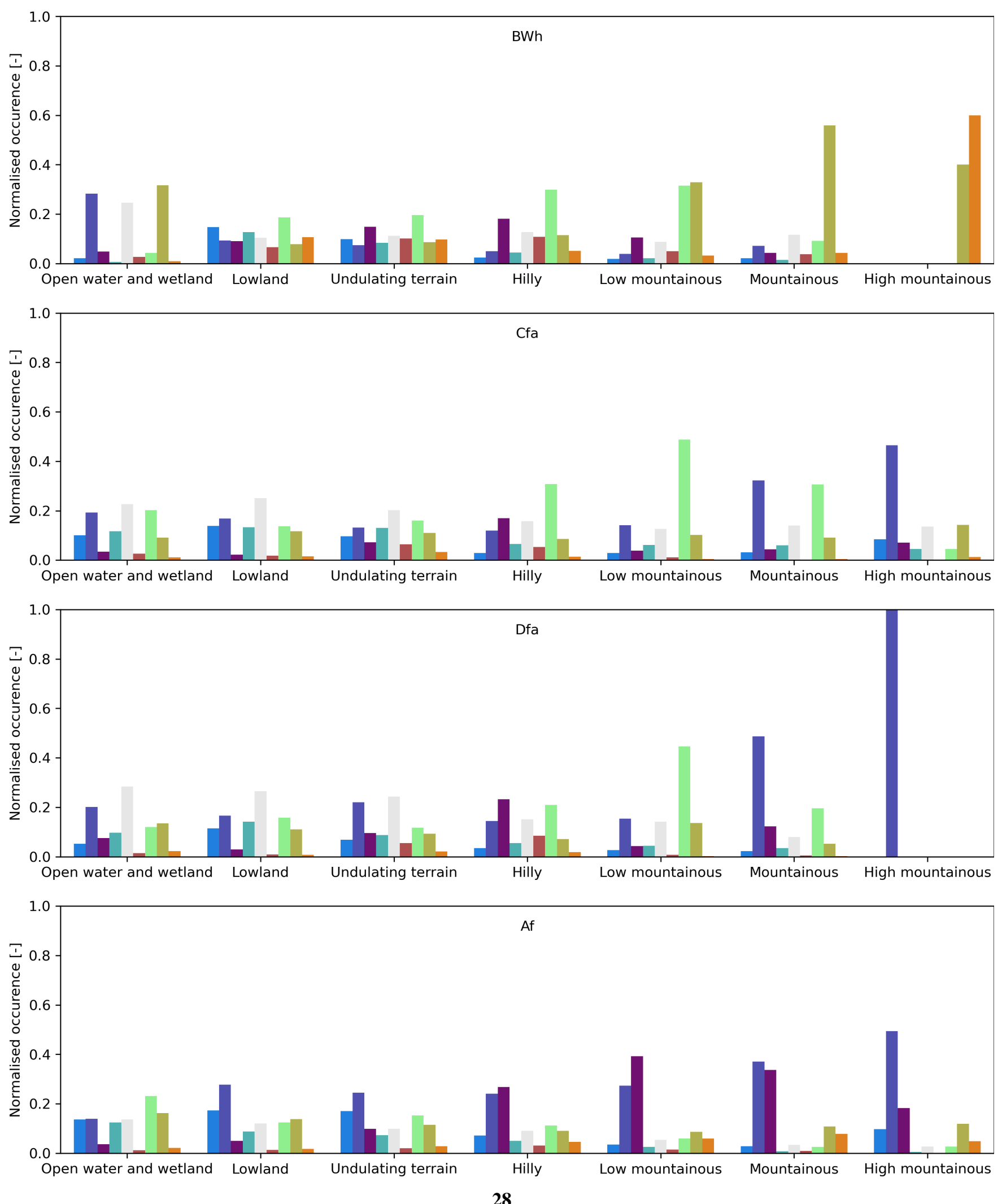

Figure S27. Distribution of ecohydrological classes in the four climate zones discussed in the main text. 